\title{
Investigating self-care performance of diabetic patients at a diabetes center; a single center pilot study
}

\author{
Zaher Khazaei ${ }^{1}$, Hasan Naemi ${ }^{2}$, Elham Goodarzi ${ }^{3}$, Zahra Khoshakhlagh ${ }^{4}$, Salman Khazaei ${ }^{5}$, Hossein Ali Adineh ${ }^{6}$, \\ Elham Jabari ${ }^{4}$, Faezeh Soleymani ${ }^{4}$, Malihe Sohrabivafa ${ }^{7}$, Razie Hoshmand Dalir ${ }^{4}$, Victoria Momenabadi ${ }^{8}$, Mahboobe \\ Neamatshahi ${ }^{*}$
}

${ }^{1}$ Social Determinants of Health Research Center, Kurdistan University of Medical Sciences, Sanandaj, Iran ${ }^{2}$ Department of Public Health, School of Health, Sabzevar University of Medical Sciences, Sabzevar, Iran

${ }^{3}$ Social Development and Health Promotion Research Center, Gonabad University of Medical Sciences, Gonabad, Iran ${ }^{4}$ Student Research Committee, Sabzevar University of Medical Sciences, Sabzevar, Iran

${ }^{5}$ Department of Epidemiology, School of Public Health, Hamadan University of Medical Sciences, Hamadan, Iran

${ }^{6}$ Department of Epidemiology and Biostatistics, Iranshahr University of Medical Sciences, Iranshahr, Iran

${ }^{7}$ Department of Health and Community Medicine, Faculty of Medicine, Dezful University of Medical Sciences, Dezful, Iran.

${ }^{8}$ Department of Health Education and Health Promotion, School of Health, Shiraz University of Medical Sciences, Shiraz, Iran

${ }^{9}$ School of Medicine, Sabzevar University of Medical Sciences, Faculty of Medicine, Sabzevar, Iran

\section{A R T I C L E I N F O}

Article Type:

Original

\section{Article History:}

Received: 6 May 2017

Accepted: 18 September 2017

ePublished: 10 November 2017

\section{Keywords:}

Diabetes mellitus

Self-care performance

Chronic diseases

\begin{abstract}
A B S T RAC T
Introduction: Diabetes is one of the most common metabolic diseases in humans that is mainly recognized by a defect in the metabolism of carbohydrates. Diabetes self-care is one of the factors for controlling the disease.

Objectives: The aim of this study was to investigate the self-care performance of diabetic patients at the diabetes center of Sabzevar in 2014.

Patients and Methods: This is a cross-sectional, which was conducted on 400 diabetic patients to determine the patients' awareness as a raw score. The study was conducted by designing a two-part questionnaire (demographic information and performance measurement) which was completed by patients and in the case of lack of literacy by the researcher. Chi-square, $t$ test and analysis of variance (ANOVA) with CI 95\% were used for statistical analysis.

Results: Of 400 participants, 156 were female. Around $93.7 \%$ of the individuals were under diploma. Chi-square test showed education has only the significant relationship with nutritional performance. Additionally, a significant relationship between occupation and all self-care parameters was detected. There is also a significant relationship between marriage and drug performance and self-monitoring $(P<0.05)$.

Conclusion: By implementing this study, the self-care role of diabetic patients in improving disease and reducing costs was determined and its effect on improving individual and social life was confirmed.
\end{abstract}

Implication for health policy/practice/research/medical education:

Management programs for diabetes and other chronic disease are popular because they help achieve disease control and improve chronic disease outcomes. Self-care behaviors in chronic patients, i.e. diabetic patients, in developing countries is low and promoting self-care and achievement to desirable self-control in these patients is a major health concern. Given that selfcare is one of the most important factors for controlling the disease and lack of enough evidence in this regard in developing country, investigating the self-care performance of diabetic patients is necessary for considering in health policy decisions. Please cite this paper as: Khazaei Z, Namei H, Goodarzi E, Khoshakhlagh Z, Khazaei S, Jabari E, et al. Investigating self-care performance of diabetic patients at a diabetes center; a single center pilot study. J Nephropharmacol. 2018;7(1):24-31. DOI: 10.15171/npj.2018.06. 


\section{Introduction}

Until a few years ago, communicable diseases were considered as the biggest health problem in third world countries, while today, chronic diseases such as diabetes are considered a serious threat to developing countries (1). In fact, chronic diseases are one of the main health issues in new and developing communities (2). Diabetes is the most common chronic disease worldwide. The nature of this disease and its complications will impose a heavy economic burden and reduce the quality of life of the patient and his family (3). Diabetes belongs to the group of metabolic diseases $(4,5)$ and includes a group of hyperglycemic disorders $(6,7)$ which is caused by a defect in secretion or action of insulin $(8,9)$.

Diabetes is the fifth cause of death in Western communities (10) and the seventh cause of death in the United States with about 160000 deaths a year (11), and it is predicted to be in the seventh rank of the main causes of death worldwide by 2030 (12). In Iran, diabetes is at the head of non-communicable diseases (13). An increase in the prevalence of diabetes in Iran is also a warning of its undesirable control (14). The population about 100-120 million people in the world are infected with diabetes, and according to the existing statistics, its prevalence is 2.8 in urban areas of Iran and 1.2\% in rural areas (15).

According to the international federation of diabetes, if immediate measure is not taken to prevent this disease, the proportion of the individuals with diabetes will increase from 366 million people in 2011 to 552 million people in 2030 (16), and one percent will be added to the statistics of the patients with this disease annually (17).

One of the most important issues is currently governments spend a lot of cost for preventing and controlling diabetes, while, the proportion of these patients is increased day by day. The increasing proportion of diabetic patients more occur in developing countries and depends on population growth, aging, unhealthy diets, obesity and lifestyle without mobility (18).

Due to low self-care behaviors in chronic patients, an important challenge in the 21 st century is to promote selfcare and achieve desirable self-control in these patients, especially diabetic patients (19). In diabetics, patients have an important role in treating and reducing the complications of the disease, and self-care is one of the most important factors for controlling the disease (20). The diabetic patients' understanding and awareness of proper nutrition principles, food selection, strict observing the pattern of treatment, caring, doing exercise and proper physical activity along with changing lifestyle and mental health care are the factors that regulate and control metabolism and prevent the short-term complications (21).

The most important factor in controlling this chronic disease is self-care behaviors. Self-care means correct and timely insulin injection, observing the diet, regular sports activities, recognizing the symptoms of increased blood glucose, and regular consuming medications (22). Self-care improves the quality of life and is effective in reducing the costs as well as the number of hospitalization in the hospitals is reduced (23).

\section{Objectives}

Given that self-care in diabetes is one of the most important factors for controlling the disease, and the most important cause of mortality in diabetic patients is the lack of self-care. The aim of this study is to investigate the self-care performance of diabetic patients at the diabetes center of Sabzevar in 2014.

\section{Patients and Methods}

\section{Patients}

This cross-sectional descriptive-analytic study was conducted in 2015-2016. The statistical population was all diabetic patients referred to the diabetes center of Sabzevar University of Medical Sciences. The sample size was 400 subjects who were selected using a simple random method from the patients who referred to the diabetes center of Sabzevar daily.

The questionnaire consisted of two parts that first part was included demographic characteristics such as age, gender, marital status, level of education, occupation, blood glucose measurement method, blood glucose regulation method, and the number of hospitalizations in the last six months. The second part was the questions about performance measurement (nutrition 8 questions, exercise 5 questions, medicine 8 questions, self-monitoring and control 7 questions). The questions were designed as three options, hence zero score was considered for the answer rarely, 1 score for the answer sometimes, and 2 scores for the answer always. Content validity index and the comments of the experts (Delphi method) were used to determine the scientific and validity of the questionnaire. The internal consistency of the questionnaire with Cronbach's alpha coefficient was calculated 0.8 in order to determine its reliability.

To determine the measurement of the performance (nutrition, exercise, medicine, and control and monitoring), the score was classified into three groups of weak (0-3.33) moderate (3.34-6.66) well (6.67-13).

\section{Ethical issues}

The research followed the tenets of the Declaration of Helsinki and its later amendments. Patients gave their written and informed consent to participate in this investigation by completing the consent form. This research has been approved by Sabzevar University of Medical Sciences (code ethics \# Medsab.Rec.93.104).

\section{Statistical analysis}

Data were analyzed using SPSS software. Chi-square, $t$ test and analysis of variance (ANOVA) with confidence level $95 \%$ were used for statistical analysis. $P<0.05$ was 
Table 1. Demographic information of participants in the study

\begin{tabular}{llc}
\hline Variable & & No. (\%) \\
\hline \multirow{2}{*}{ Gender } & Male & $156(39)$ \\
& Female & $244(61)$ \\
& Illiterate & $215(53.7)$ \\
& Primary & $43(10.7)$ \\
Education & Intermediate & $69(17.2)$ \\
& High school & $25(6.4)$ \\
Marital & University & $48(12)$ \\
& Single & $23(5.7)$ \\
& Married & $368(92)$ \\
Occupational & Other & $9(2.3)$ \\
& Housewife & $228(57)$ \\
& Employed & $137(34.3)$ \\
& Unemployed & $35(8.7)$ \\
\hline
\end{tabular}

considered as the significance level.

Results

We found, more than half of the participants were male with elementary education. Around, 92\% of the participants were married and only $34.3 \%$ of them were employed (Table 1).

Furthermore, $77.5 \%$ of the subjects were rarely used nutrition to control diabetes and $86.7 \%$ of the individuals sometimes use insulin drugs to control diabetes. Accordingly $52.5 \%$ of the individuals rarely use selfmonitoring and control performance to control their diabetes, and more than half of the participants (71.3\%) sometimes use sport activities to control their diabetes (Figure 1).

Moreover, a statistically significant relationship between gender, marital status, education and blood glucose measurement methods was detected $(P=0.002)$. Accordingly, a statistically significant relationship between occupation and methods of regulating of blood glucose $(P<0.05)$ was seen, while no statistically significant relationship between gender, education, marital status and methods of regulating of blood glucose was found $(P>0.05)$. Likewise, we found a statistically significant relationship between gender, education, occupation and the number of hospitalization in the hospitals $(P<0.05)$ (Table 2).

In this study, we found mean score of nutritional performance is different in two groups of diabetic women and men, while mean score in men is higher than women $(P<0.05)$, and there was no statistically significant difference between the mean score of other performances in men and women $(P>0.05)$. Similarly, there was a statistically significant difference between nutrition and sports performance at different levels of education, and the mean scores are higher in the individuals with higher education $(P<0.05)$. There was also a statistically significant difference between the mean score of drug performance in married and single individuals $(P<0.05)$, hence, the mean score in married individuals was higher than single individuals $(P<0.05)$. In addition a statistically significant difference between the mean score of sports performance in the housewives, employed and unemployed individuals was detected while the mean score is higher in the housewives $(P<0.05)$ (Table 3$)$. To detect the self-care dimensions, we found a significant relationship between level of education and marital status and nutritional performance of diabetic patients $(P<0.05)$. Likewise, to detect drug performance, we also found a significant relationship between the individuals' occupation and marital status with insulin injection to control diabetes $(P<0.05)$. Moreover, a significant relationship between sports performance to control blood glucose, gender, education, marital status and patients' occupation was seen $(P<0.05)$. To investigate the performance of self-monitoring and diabetes control, the study showed a significant relationship between the individuals' gender, occupation, and marital status and also the performance of self-monitoring with control of diabetic patients $(P<0.05)$ (Table 4$)$.

\section{Discussion}

Self-care is the most important determinant factor of the status of diabetes control. It is a concept that requires

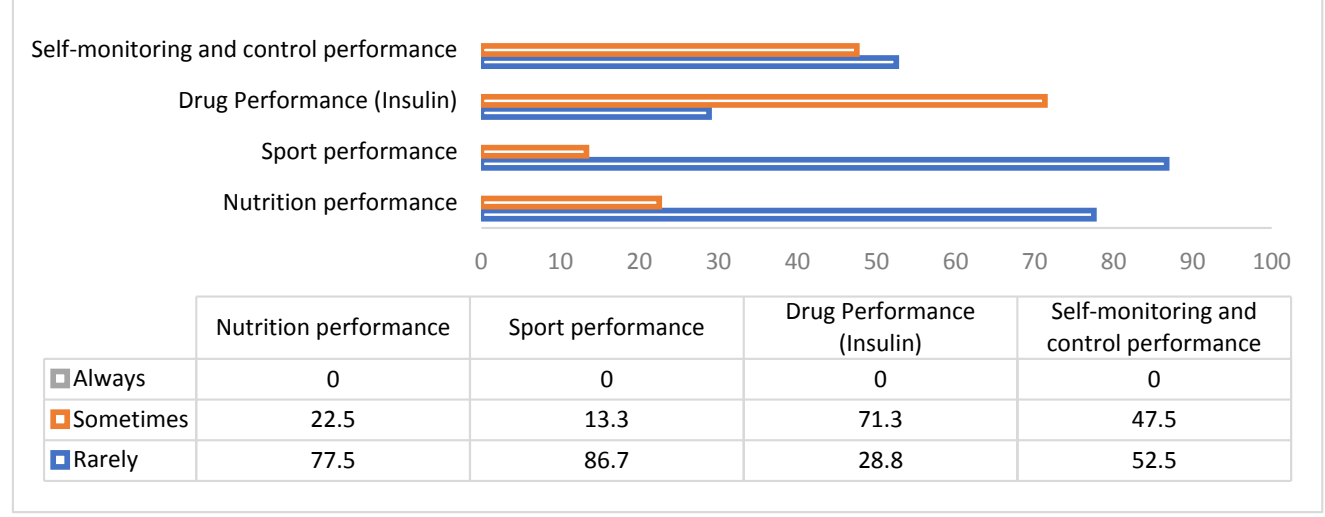

Figure 1. Investigating self-care performances. 
Table 2. Relationship blood glucose measurement methods, regulating blood glucose and number of hospitalization to demographic information

\begin{tabular}{|c|c|c|c|c|c|c|c|c|c|c|c|c|c|c|c|c|}
\hline \multirow[b]{2}{*}{ Variable } & & \multicolumn{3}{|c|}{ Number of admissions } & \multirow[b]{2}{*}{$x^{2}$} & \multirow[b]{2}{*}{$P$} & \multicolumn{3}{|c|}{$\begin{array}{l}\text { The method of measuring blood } \\
\text { sugar }\end{array}$} & \multirow[b]{2}{*}{$x^{2}$} & \multirow[b]{2}{*}{$P$} & \multicolumn{3}{|c|}{$\begin{array}{l}\text { Blood sugar control } \\
\text { methods }\end{array}$} & \multirow[b]{2}{*}{$x^{2}$} & \multirow[b]{2}{*}{$P$} \\
\hline & & 1 & $2-3$ & $>3$ & & & $\begin{array}{l}\text { Blood } \\
\text { glucose }\end{array}$ & $\begin{array}{l}\text { Urine test } \\
\text { strip }\end{array}$ & Laboratory & & & Diet & $\begin{array}{l}\text { Oral } \\
\text { pills }\end{array}$ & Insulin & & \\
\hline \multirow{2}{*}{ Gender } & Male & 29.5 & 23.1 & 47.4 & \multirow{2}{*}{13.2} & \multirow{2}{*}{0.01} & 34 & 21.2 & 44.9 & \multirow{2}{*}{12.3} & \multirow{2}{*}{0.02} & 12.2 & 12.2 & 75.6 & \multirow{2}{*}{5.6} & \multirow{2}{*}{0.1} \\
\hline & Female & 25.8 & 11.1 & 63.1 & & & 28.7 & 10.7 & 60.7 & & & 21.3 & 12.3 & 66.4 & & \\
\hline \multirow{3}{*}{$\begin{array}{l}\text { Marital } \\
\text { status }\end{array}$} & Single & 34.8 & 8.7 & 56.5 & \multirow{3}{*}{5.5} & \multirow{3}{*}{0.2} & 39.1 & 0 & 60.9 & \multirow{3}{*}{9.01} & \multirow{3}{*}{0.06} & 17.4 & 0 & 82.6 & \multirow{3}{*}{4.5} & \multirow{3}{*}{0.3} \\
\hline & Married & 27.2 & 16.6 & 56.3 & & & 30.7 & 16 & 53.3 & & & 17.7 & 12.8 & 69.6 & & \\
\hline & Other & 11.1 & 0 & 88.9 & & & 11.1 & 0 & 88.9 & & & 22.2 & 22.2 & 55.6 & & \\
\hline \multirow{5}{*}{ Education } & Illiterate & 18.8 & 18.8 & 62.5 & \multirow{5}{*}{16.6} & \multirow{5}{*}{0.03} & 20.8 & 14.6 & 64.6 & \multirow{5}{*}{19.2} & \multirow{5}{*}{0.01} & 27.1 & 18.8 & 54.2 & \multirow{5}{*}{13} & \multirow{5}{*}{0.1} \\
\hline & Primary & 27 & 11.6 & 61.4 & & & 29.8 & 12.1 & 58.1 & & & 20 & 10.2 & 69.8 & & \\
\hline & Intermediate & 32.6 & 11.6 & 55.8 & & & 37.2 & 7 & 55.8 & & & 9.3 & 16.3 & 74.4 & & \\
\hline & High school & 26.1 & 24.6 & 49.3 & & & 30.4 & 24.6 & 44.9 & & & 10.1 & 10.1 & 79.7 & & \\
\hline & University & 40 & 28 & 32 & & & 48 & 24 & 28 & & & 16 & 16 & 68 & & \\
\hline \multirow{3}{*}{ Occupation } & Housewife & 24.6 & 10.5 & 64.9 & \multirow{3}{*}{16.8} & & 26.3 & 11 & 62.7 & & & 22.4 & 13.2 & 64.5 & & \\
\hline & Employed & 31.4 & 23.4 & 45.3 & & 0.02 & 35 & 21.9 & 43.1 & 17.7 & 0.01 & 12.4 & 12.4 & 75.2 & 10 & 0.3 \\
\hline & Unemployed & 28.6 & 20 & 51.4 & & & 42.9 & 11.4 & 45.7 & & & 8.6 & 5.7 & 85.7 & & \\
\hline
\end{tabular}

Table 3. The relationship between self-care performance and demographic variables

\begin{tabular}{|c|c|c|c|c|c|}
\hline Variable & & Nutrition performance & Sport performance & Drug Performance (Insulin) & Self-monitoring and control performance \\
\hline \multirow{4}{*}{ Sex } & Male & $8.3 \pm 2.1$ & $11.2 \pm 4.1$ & $12.4 \pm 2.3$ & $7.6 \pm 2.1$ \\
\hline & Female & $9.7 \pm 2.5$ & $10.8 \pm 4.3$ & $12.8 \pm 2.6$ & $7.8 \pm 2.4$ \\
\hline & Total & $8.6 \pm 2.2$ & $10.9 \pm 4.2 \pm$ & $12.6 \pm 2.3$ & $7.7 \pm 2.3$ \\
\hline & $P$ value & 0.01 & 0.2 & 0.1 & 0.8 \\
\hline \multirow{7}{*}{ Education } & Illiterate & $8.3 \pm 2.5$ & $11.11 \pm 4.3$ & $12.8 \pm 5$ & $7.7 \pm 2$ \\
\hline & Primary & $8.8 \pm 2.3$ & $10.3 \pm 4.5$ & $11.8 \pm 4.8$ & $7.3 \pm 1.9$ \\
\hline & Intermediate & $8.6 \pm 2.5$ & $10.2 \pm 4.1$ & $12.3 \pm 5.2$ & $7.3 \pm 2.1$ \\
\hline & High school & $9.5 \pm 2.4$ & $8.7 \pm 4$ & $14.2 \pm 4.2$ & $7.8 \pm 1.6$ \\
\hline & University & $9.6 \pm 2.3$ & $11.4 \pm 3.9$ & $13 \pm 4.7$ & $8 . \pm .9$ \\
\hline & Total & $8.6 \pm 2.5$ & $10.7 \pm 4.3$ & $12.7 \pm 4.9$ & $7.6 \pm 1.9$ \\
\hline & $P$ value & 0.006 & 0.04 & 0.1 & 0.1 \\
\hline \multirow{5}{*}{ Marital } & Single & $9.2 \pm 3.1$ & $10.7 \pm 4.7$ & $8.9 \pm 4.6$ & $6.7 \pm 1.6$ \\
\hline & Married & $8.6 \pm 2.5$ & $10.7 \pm 4.2$ & $12.9 \pm 4.9$ & $7.7 \pm 2.01$ \\
\hline & Other & $8.4 \pm 3$ & $13.7 \pm 3.3$ & $14.8 \pm 3.7$ & $8 \pm 1.41$ \\
\hline & Total & $8.6 \pm 2.5$ & $10.7 \pm 4.3$ & $12.7 \pm 4.9$ & $7.6 \pm 1.9$ \\
\hline & $P$ value & 0.4 & 0.1 & 0.001 & 0.06 \\
\hline \multirow{5}{*}{ Occupational } & Housewife & $8.8 \pm 2.6$ & $11.4 \pm 4.2$ & $12.8 \pm 5.1$ & $7.6 \pm 2$ \\
\hline & Employed & $8.5 \pm 2.3$ & $9.7 \pm 4.1$ & $12.7 \pm 4.7$ & $7.6 \pm 1.9$ \\
\hline & Unemployed & $7.8 \pm 2.1$ & $10 \pm 4.2$ & $11.7 \pm 5.1$ & $7.8 \pm 2$ \\
\hline & Total & $8.6 \pm 2.5$ & $10.7 \pm 4.3$ & $12.7 \pm 4.9$ & $7.6 \pm 1.9$ \\
\hline & $P$ value & 0.07 & 0.001 & 0.4 & 0.7 \\
\hline
\end{tabular}

more investigation in diabetic patients and is important not only for health, but also for economic analysis of the community (19). Blood glucose control of these patients in normal range will significantly reduce complications and entail the patient's proper self-care (24). Therefore, the international federation of diabetes recommends that the patients take self-care measures to control desirably their blood glucose (25).

Among the factors affecting blood glucose control, the role of other variables such as age, gender, marital status, level of education, and family factors cannot be ignored in addition to drug administration and observing therapeutic diet (26).

The results of this study showed that $77.5 \%$ of the subjects were rarely used nutrition to control diabetes and $86.7 \%$ of the individuals sometimes use insulin drugs to control diabetes, and (71.3\%) sometimes use sport activities to control their diabetes. The results of this study showed that there is a significant relationship between gender and the number of hospitalizations and methods of measuring 
Table 4. The relationship between self-care dimensions and demographic variables

\begin{tabular}{|c|c|c|c|c|c|c|c|c|c|}
\hline \multirow[b]{2}{*}{ Variable } & & \multicolumn{2}{|c|}{ Nutrition performance } & \multicolumn{2}{|c|}{ Drug Performance (Insulin) } & \multicolumn{2}{|c|}{ Sport performance } & \multicolumn{2}{|c|}{$\begin{array}{c}\text { Self-monitoring and control } \\
\text { performance }\end{array}$} \\
\hline & & $\begin{array}{l}\text { Rarely, } \\
\text { No. (\%) }\end{array}$ & $\begin{array}{l}\text { Sometimes } \\
\text { No. (\%) }\end{array}$ & $\begin{array}{l}\text { Rarely } \\
\text { No. (\%) }\end{array}$ & $\begin{array}{l}\text { Sometimes } \\
\text { No. (\%) }\end{array}$ & $\begin{array}{l}\text { Rarely } \\
\text { No. (\%) }\end{array}$ & $\begin{array}{l}\text { Sometimes } \\
\text { No. (\%) }\end{array}$ & $\begin{array}{l}\text { Rarely } \\
\text { No. (\%) }\end{array}$ & $\begin{array}{l}\text { Sometimes } \\
\text { No. (\%) }\end{array}$ \\
\hline \multirow{3}{*}{ Gender } & Male & $125(80.1)$ & $1(19.9)$ & $142(91)$ & $14(9)$ & $105(67.3)$ & $51(32.7)$ & 81 (51.9) & $75(48.1)$ \\
\hline & Female & $185(75.8)$ & $185(24.2)$ & $(205) 84$ & $39(16)$ & $180(73.8)$ & $64(26.2)$ & 129 (52.9) & $118(47.1)$ \\
\hline & $P$ value & & 0.01 & & 0.03 & & 0.02 & & 0.02 \\
\hline \multirow{6}{*}{ Education } & Illiterate & $43(89.6)$ & $5(10.4)$ & $45(93.8)$ & $3(6.3)$ & $38(79.2)$ & $10(20.8)$ & $31(64.6)$ & $17(35.4)$ \\
\hline & Primary & $155(60)$ & 60 (27.9) & $184(85.6)$ & $31(14.4)$ & $156(72.6)$ & $59(27.4)$ & 118 (54.9) & $97(45.1)$ \\
\hline & Intermediate & $35(81.4)$ & $8(18.6)$ & $37(86)$ & $6(14)$ & $27(62.8)$ & $16(37.2)$ & $17(39.5)$ & $26(60.5)$ \\
\hline & High school & $55(79.7)$ & $14(20.3)$ & $57(82.6)$ & $12(17.4)$ & $50(72.5)$ & 27.5) 19) ) & 31 (44.9) & $38(55.1)$ \\
\hline & University & $22(88)$ & $3(12)$ & $24(96)$ & $1(4)$ & $14(56)$ & $11(44)$ & $13(52)$ & $12(48)$ \\
\hline & $P$ value & & 0.02 & & 0.3 & & 0.02 & & 0.3 \\
\hline \multirow{4}{*}{ Marital } & Single & $19(82.6)$ & $4(17.4)$ & $15(65.2)$ & $8(34.8)$ & $14(60.9)$ & 9 (39.1) & $6(26.1)$ & 17 (73.9) \\
\hline & Married & $285(77.4)$ & $83(22.6)$ & $323(87.8)$ & $15(65.2)$ & $23(71.5)$ & $105(28.5)$ & $198(53.8)$ & $170(46.2)$ \\
\hline & Other & $6(66.7)$ & $3(33.3)$ & $9(100)$ & $0(0)$ & $8(88.9)$ & 1 (11.1) & $6(66.7)$ & $3(33.3)$ \\
\hline & $P$ value & & 0.01 & & 0.01 & & 0.02 & & 0.01 \\
\hline \multirow{4}{*}{ Occupational } & Housewife & $177(77.6)$ & $51(22.4)$ & $191(83.8)$ & $37(16.2)$ & $172(75.5)$ & $56(24.6)$ & 119 (52.5) & $109(47.8)$ \\
\hline & Employed & $108(78.8)$ & $19(21.2)$ & 92.7) 127) ) & $10(7.3)$ & $89(65)$ & $48(35)$ & $72(52.6)$ & 65947.4) \\
\hline & Unemployed & $2(71.4)$ & $10(28.6)$ & 29 (82.9) & $6(17.1)$ & $24(68.6)$ & $11(31.4)$ & $19(54.3)$ & $16(45.7)$ \\
\hline & $P$ value & & 0.2 & & 0.01 & & 0.01 & & 0.01 \\
\hline
\end{tabular}

blood glucose $(P<0.05)$. In investigating the self-care dimensions, the results of the study showed that there is a significant relationship between the level of education, marital status and nutritional performance, between the individuals' marital status and occupation and insulin injections, between the sports performance and gender and education, between self-monitoring and control performance and the individuals' gender, marital status and occupation to control diabetes disease $(P<0.05)$. The highest mean score of performance was related to the self-monitoring and control performance, and the lowest mean score was related to the nutritional performance. We found a significant relationship between the score of self-care performances and gender. Additionally self-care behaviors in men were better than women. Men had better caring behaviors than women in the studies of Akyol et al (27), Abootalebi et al (28), Bonds et al (29) and Bai et al (30) which were consistent with our study. There was also a significant relationship between self-care performance and gender in the study of Naghibi et al. However, their result was not consistent with our finding (31). There was no relationship between gender and self-care in the studies of Baghaei et al and Hatamloo et al $(32,33)$. The difference between self-care in men and women can be attributed to the factors such as awareness level and physical and mental status of the individuals.

The results of the above study showed that there is a statistically significant relationship between sports, drug, control, and self-control performance and the occupation of diabetic patients $(P<0.05)$. There was no statistically significant relationship between self-care and occupation in the study of Naghibi et al which these results were not consistent with our study (31). The importance of the type of occupation in promoting the level of self-care has been mentioned in the study of Abdel-Gawad (34).

The results of the above study showed a statistically significant relationship between self-care performance and education. Hence, those who had lower education had more inappropriate self-care performance than other patients. These results were consistent with the results of the studies of Zandkarimi et al (35), Vosoghi Karkazloo et al (36), Akyol et al (27), Jafarian et al (37), Chang et al (38), DeWalt and Hink (39), Osborn and Egede (40) and Sloan et al (41). The patients with higher levels of education have more awareness of the disease and its complications and how the diet is important and how to take medication and also the importance of sports activities in controlling blood glucose. High education facilitates self-management and self-care of the disease, while low education faces the process of self-care with serious problems. Therefore, training should be emphasized in the groups with the lower level of literacy. Since self-care in diabetes is one of the important issues for controlling the disease, training programs can have positive effects on the control of diabetes in patients $(42,43)$. The results of the above study showed a statistically significant relationship between the self-care performance and marital status. These results were consistent with the results of the study of Baghaei et al $(P<0.05)(32)$.

Investigations have shown that one of the aspects of self- 
care is paying attention to the diet and physical activity. Today, the specialists define the physical activities along with observing the diet and drug consumption as the third fundamental bases in the treatment of diabetes (44). Meanwhile, an important fact that the health care providers should take into consideration is nonpharmacological treatment strategies that if they do not have more value than pharmacological treatment, they will be equally effective in the treatment and prevention of the complications (45). The results of our study showed that most participants in the study $(75.6 \%)$ use insulin to control blood glucose. Changing the behaviors such as the physical activity is far more difficult, because these behaviors are influenced by the processes such as the patient conditions, individual interests, culture and customs, while the patients are less influenced by the intended processes, therefore, most patients use insulin to control their disease (46). One of the other reasons which can be mentioned for the acceptable performance of the patients after taking prescribed medications is the patients' belief in the method of disease control. Most people believe that they should take medication to treat the disease when they get sick, while they have a weak belief in making some changes in lifestyle (47).

Focusing on self-control in the chronic diseases is the basis of diabetic patient care model and guiding patients through training and support towards the self-centered can improve the control of this disease and reduce the cost of care (48). While there was no statistically significant difference between the mean of self-control and monitoring performance and gender, educational levels, occupation and marital status in our study. Therefore, conducting the studies at a larger level and larger sample size can show this difference better.

\section{Conclusion}

The attitude and performance of the diabetic patients will be better to the disease with increasing their literacy that this, in turn, is important in preventing the complications of the disease and controlling the disease. Training the patients to acting on a proper diet and physical activity to reduce blood glucose can be a good modality to reduce the cost of treatment as well as a definitive way to achieve normal blood glucose.

\section{Study limitations}

Small sample size can be mentioned as the limitation of this study. We suggest more studies on this aspect of diabetic patients.

\section{Acknowledgments}

The authors of the paper express their sincere gratitude to all diabetic patients who participated in this study as well as all respected staffs employed in the diabetes clinic of Sabzevar city.

\section{Authors' contribution}

$\mathrm{HN}, \mathrm{ZKH}$, SKH and EG made a substantial contribution to the conception, design, analysis and interpretation of data. MS and SD were involved in drafting the manuscript and revising it critically for important intellectual content. ZKH, SLD, FS and RH collected data. SKH, SK, HAA, EJ, FS and MS revised the manuscript critically for important intellectual content. All authors read and signed the final manuscript.

\section{Conflicts of interest}

The authors declare no conflict of interest.

\section{Ethical considerations}

Ethical issues (including plagiarism, data fabrication, double publication) have been completely observed by the authors.

\section{Funding/Support}

This research has been funded by Sabzevar University of Medical Sciences (Ethical No. Medsab.Rec.93.104).

\section{References}

1. Rahimi M, Dinari Z, Najafi F. Prevalence of gestational diabetes and its risk factors in Kermanshah 2009. Behbood J. 2010;14:244-50.

2. Shaw JE, Sicree RA, Zimmet PZ. Global estimates of the prevalence of diabetes for 2010 and 2030. Diabetes Res Clin Pract. 2010;87:4-14. doi: 10.1016/j.diabres.

3. Susan van D, Beulens JW, Yvonne T. van der S, Grobbee DE, Nealb B. The global burden of diabetes and its complications: an emerging pandemic. Eur J Prev Cardiol. 2010;17:3-8

4. Group NDD. Classification and diagnosis of diabetes mellitus and other categories of glucose intolerance. Diabetes. 1979;28:1039-57.

5. Ferrannini E, Baldi S, Frascerra S, Astiarraga B, Heise T, Bizzotto R, et al. Shift to fatty substrate utilization in response to sodium-glucose cotransporter 2 inhibition in subjects without diabetes and patients with type 2 diabetes. Diabetes. 2016;65:1190-5.

6. Al-Rubeaan K, Youssef AM, Ibrahim HM, Al-Sharqawi AH, AlQumaidi H, AlNaqeb D, et al. All-cause mortality and its risk factors among type 1 and type 2 diabetes mellitus in a country facing diabetes epidemic. diabetes research and clinical practice. Diabetes Res Clin Pract. 2016;118:130-9. doi: 10.1016/j.diabres.2016.06.012.

7. Handelsman Y, Bloomgarden ZT, Grunberger G, Umpierrez G, Zimmerman RS, Bailey TS, et al. American Association of Clinical Endocrinologists and American College of Endocrinology-clinical practice guidelines for developing a diabetes mellitus comprehensive care plan-2015. Endocr Pract. 2015;21:1-87. doi: 10.4158/EP15672.

8. Guariguata L, Whiting D, Hambleton I, Beagley J, Linnenkamp U, Shaw J. Global estimates of diabetes prevalence for 2013 and projections for 2035. Diabetes Res Clin Pract. 2014;103:13. doi: 10.1016/j.diabres.2013.11.002. 
9. Schwingshackl L, Missbach B, König J, Hoffmann G. Adherence to a Mediterranean diet and risk of diabetes: a systematic review and meta-analysis. Public Health Nutr. 2015;18:1292-9. doi: 10.1017/S1368980014001542.

10. DeBoer MD. Obesity, systemic inflammation, and increased risk for cardiovascular disease and diabetes among adolescents: a need for screening tools to target interventions. Nutrition. 2013;29:379-86. doi: 10.1016/j. nut.2012.07.003.

11. Wanner C, Inzucchi SE, Lachin JM, Fitchett D, von Eynatten $\mathrm{M}$, Mattheus $\mathrm{M}$, et al. Empagliflozin and progression of kidney disease in type 2 diabetes. $\mathrm{N}$ Engl J Med. 2016;375:323-34. doi. 10.1056/NEJMoa1515920.

12. Nentwich MM, Ulbig MW. Diabetic retinopathy-ocular complications of diabetes mellitus. World J Diabetes 2015;6:489. doi: 10.4239/wjd.v6.i3.489.

13. Esteghamati A, Gouya MM, Abbasi M, Delavari A, Alikhani $S$, Alaedini F, et al. Prevalence of diabetes and impaired fasting glucose in the adult population of Iran. Diabete Care. 2008;31:96-8. doi: 10.2337/dc07-0959.

14. Amini M, Parvaresh E. Prevalence of macro-and microvascular complications among patients with type 2 diabetes in Iran: a systematic review. Diabetes Res Clin Pract. 2009;83:18-25. doi: 10.1016/j.diabres.

15. Lotfi MH, Saadati H, Afzali M. Prevalence of diabetes in people aged $\geq 30$ years: the results of screen-ing program of Yazd Province, Iran, in 2012. J Res Health Sci . 2013;14:8892.

16. Papatheodorou K, Banach M, Edmonds M, Papanas N, Papazoglou D. Complications of diabetes. World J Diabetes. 2015;15:489-499. doi: 10.4239/wjd.v6.i3.489.

17. Murray CJ, Barber RM, Foreman KJ, Ozgoren AA, AbdAllah F, Abera SF, et al. Global, regional, and national disability-adjusted life years (DALYs) for 306 diseases and injuries and healthy life expectancy (HALE) for 188 countries, 1990-2013: quantifying the epidemiological transition. Lancet. 2015;386:2145-91.

18. van Dam HA, Van der Horst F, Van den Borne B, Ryckman $\mathrm{R}$, Crebolder H. Provider-patient interaction in diabetes care: effects on patient self-care and outcomes: a systematic review. Patient Educ Couns. 2003;51:17-28. doi: 10.1016/ S0738-3991(02)00122-2.

19. van Son J, Nyklíček I, Pop VJ, Blonk MC, Erdtsieck RJ, Spooren PF, et al. The effects of a mindfulness-based intervention on emotional distress, quality of life, and HbAlc in outpatients with diabetes (DiaMind). Diabetes Care. 2013;36:823-30. doi: 10.2337/dc12-1477.

20. Mitranun W, Deerochanawong C, Tanaka H, Suksom D. Continuous vs interval training on glycemic control and macro-and microvascular reactivity in type 2 diabetic patients. Scand J Med Sci Sports. 2014;24(2),69-76. doi: $10.1111 / \mathrm{sms} .12112$

21. Pandit AU, Bailey SC, Curtis LM, Seligman HK, Davis TC, Parker RM, et al. Disease-related distress, self-care and clinical outcomes among low-income patients with diabetes. J Epidemiol Community Health. 2014;2:86-92. doi: 10.1136/jech-2013-203063.

22. Gonzalez JS, Safren SA, Cagliero E, Wexler DJ, Delahanty L, Wittenberg E, et al. Depression, self-care, and medication adherence in type 2 diabetes. Diabetes Care. 2007;30:22227. doi: $10.2337 / \mathrm{dc} 07-0158$.

23. Shrivastava SR, Shrivastava PS, Ramasamy J. Role of selfcare in management of diabetes mellitus. J Diabetes Metab Disord. 2013;12:14. doi: 10.1186/2251-6581-12-14.

24. Tabatabaei-Malazy O, Mohajeri-Tehrani M, Madani S, Heshmat R, Larijani B. The prevalence of diabetic peripheral neuropathy and related factors. Iran J Public Health. 2011;40(3):55.

25. Tang TS, Brown MB, Funnell MM, Anderson RM. Social support, quality of life, and self-care behaviors among African Americans with type 2 diabetes. Diabetes Educ. 2008;34:266-76. doi: 10.1177/0145721708315680.

26. Heydari I, Radi V, Razmjou S, Amiri A. Chronic complications of diabetes mellitus in newly diagnosed patients. Int J Diabetes Mellit. 2010;2:61-3. doi: 10.1016/j. ijdm.2009.08.001

27. Akyol AD, Cetinkaya Y, Bakan G, Yaralı S, Akkuş S. Selfcare agency and factors related to this agency among patients with hypertension. J Clin Nurs. 2007;16:679-87. doi: $\quad 10.1111 / \mathrm{j} .1365-2702.2006 .01656 . \mathrm{x}$

28. Abootalebi G, Vosooghi N, Mohammad Nejad E, Namadi M, Akbari Kaji M. Study of the self-care agency in patients with heart failure. Crit Care Nurs. 2012;4:203-8.

29. Bonds DE, Camacho F, Bell RA, Duren-Winfield VT, Anderson RT, Goff DC. The association of patient trust and self-care among patients with diabetes mellitus. Fam Pract. 2004;5:26. doi: 10.1186/1471-2296-5-26.

30. Bai YL, Chiou CP, Chang YY. Self-care behaviour and related factors in older people with Type 2 diabetes. J Clin Nurs. 2009;18:3308-15. doi: 10.1111/j.1365-2702.2009.02992.x.

31. Naghibi SA, Asghari M, Rostami F. Investigation the effect of education on self-care promotion in type 2 diabetic patients in Noor health centers in 2015. Journal of Health Research in Community. 2015;1:22-8.

32. Baghaei $\mathrm{P}$, Zandi $\mathrm{M}$, Vares Z, Masoodialavi N, Adidhajbagheri M. Self-care behaviour of patients with diabetes in Kashan centers of diabetes. Feiz. 2008;12:88-93.

33. Hatamloo Sadabadi M, Babapour Kheirodin J. Comparison of quality of life and coping strategies in diabetic and non diabetic people. Journal of Shahid Sadoughi University of Medical Sciences. 2013;20:581-92.

34. Abdel-Gawad ES. Quality of life In Saudis with diabetes. Saudi J Disabil. 2002;8:163-8.

35. Zandkarimi E, Safavi AA, Rezaei M, Rajabi G. Comparison logistic regression and discriminant analysis in identifying the determinants of type 2 diabetes among prediabetes of Kermanshah rural areas. J Kermanshah Univ Med Sci. 2013;17:300-8. doi: 10.22110/jkums.v17i5.951

36. Vosoghi Karkazloo N, Abootalebi Daryasari G, Farahani B, Mohammadnezhad E, Sajjadi A. The study of self-care agency in patients with diabetes (Ardabil). Modern Care Journal. 2012;8:197-204.

37. Jafarian AS, Zabihi A, Babaieasl F, Eshkevari N, Bijani A. Self care behaviors in diabetic patients referring to diabetes clinics in Babol city, Iran. Journal of Babol University of Medical Sciences. 2010;12:72-8

38. Chang H-Y, Chiou C-J, Lin M-C, Lin S-H, Tai T-Y. A population study of the self-care behaviors and their 
associated factors of diabetes in Taiwan: results from the 2001, National Health Interview Survey in Taiwan. Prev Med. 2005;40:344-8 doi: 10.1016/j.ypmed.2004.06.012.

39. DeWalt DA, Hink A. Health literacy and child health outcomes: a systematic review of the literature. Pediatrics. 2009;124:S265-S74.

40. Osborn CY, Egede LE. Validation of an InformationMotivation-Behavioral Skills model of diabetes self-care (IMB-DSC). Patient Educ Couns. 2010;79:49-54. doi: 10.1016/j.pec.2009.07.016.

41. Sloan FA, Padrón NA, Platt AC. Preferences, beliefs, and selfmanagement of diabetes. Health Serv Res. 2009;44:1068-87. doi: 10.1111/j.1475-6773.2009.00957.

42. Sigurðardóttir ÁK. Self-care in diabetes: model of factors affecting self-care. J Clin Nurs. 2005;14:301-14 doi: 10.1111/j.1365-2702.2004.01043.x.

43. Perrin KM, Burke SG, O'Connor D, Walby G, Shippey C, Pitt $S$, et al. Factors contributing to intervention fidelity in a multi-site chronic disease self-management program. Implement Sci. 2006;1:26. doi: 10.1186/1748-5908-1-26.
44. Ghazanfari Z, Niknami S, Ghofranipour F, Larijani B. Regular physical activity from perspective of females with diabetes: a qualitative study. Horizon Med Sci. 2009;15(1):514 .

45. Cornell S, Briggs A. Newer treatment strategies for the management of type 2 diabetes mellitus. J Pharm Pract. 2004;17:49-54. doi: 10.1177/0897190003261308.

46. Bigdeli MA, Hashemi Nazari SS, Khodakarim S, Brodati H, Mafi H. Factors associated with self-care behavior in patients with type II diabetes. J Mazandaran Uni Med Sci. 2015;25:61-72.

47. Rahimian Bougar I, Besharat M. Mohajeri tehrani MR, Talepasand S. Direct and indirect impacts of knowledge about diabetes and social support on self-management of diabetes. Contemp Educ Pshychol. 2011:6:37-48. doi: 10.1111/j.1464-4591.2011.03485.x.

48. Parham M, Rasooli A, Safaeipour R, Mohebi S. Assessment of effects of self-caring on diabetic patients in Qom diabetes association 2013. J Sabzevar Uni Med Sci. 2014;21:473-84.

Copyright $\odot 2018$ The Author(s); Published by Society of Diabetic Nephropathy Prevention. This is an open-access article distributed under the terms of the Creative Commons Attribution License (http://creativecommons.org/licenses/by/4.0), which permits unrestricted use, distribution, and reproduction in any medium, provided the original work is properly cited. 